\title{
SYNTHESIS OF FERRITE NANOPARTICLES WITH PROTEIN MOLECULES IMMOBILLIZED ON THEIR SURFACES
}

\author{
Tran Hoang Hai, Le Hong Phuc, Doan Thi Kim Dung, \\ Nguyen Thi Le Huyen, Bui Duc Long \\ Institue of Physics in Ho Chi Minh City, \\ 01 Mac Dinh Chi Str., Dist. 1, Ho Chi Minh City, Vietnam \\ Nguyen Tien Thang*, Vu Van Do, Nguyen Thi Nhu Quynh \\ Institute of Tropical Biology, \\ 01 Mac Dinh Chi str., dist. 1, Ho Chi Minh City, Vietnam \\ Masanori Abe \\ Tokyo Institue of Technology, \\ 2-12-1 O-okayama, Meguro-ku, Tokyo 152-8552, Japan
}

Received 20 December 2005

\begin{abstract}
The ferrite $\left(\mathrm{a} \mathrm{Fe}_{3} \mathrm{O}_{4}-\gamma \mathrm{Fe}_{2} \mathrm{O}_{3}\right.$ mixed solution) fine particles, $\sim 8 \mathrm{~nm}$ in size were synthesized from an aqueous solution. Trypsin, a proteolytic enzyme or a protein, was immobilized onto the surfaces of those particles during the synthesis process. The process was performed in the open air at a temperature as low as $4^{\circ} \mathrm{C}$ and on near-neutral condition of $\mathrm{pH} \leq 9$, which is compatible with most of the bioactive molecules as well as trypsin. Therefore this technique is advantageous for preparing magnetite particles having biomolecules immobilized on their surfaces, which will be used for biomedical applications utilizing magnetic separation technique.
\end{abstract}

\section{INTRODUCTION}

Ferrite fine particles with bioactive molecules (i.e., enzyme, antibody, DNA, etc.) immobilized on their surfaces are attracting interest because of their promising biomedical applications utilizing magnetic separation technique [1]. The biomolecule immobilization onto the particle surfaces requires, in general, complicated chemical modifications of the surfaces. This article describes a technique by which the biomolecule is immobilized directly (requiring no chemical modification) onto the surfaces of the ferrite nanosized particles during the process in which the ferrite particles are synthesized from an aqueous solution. We immobilized trypsin, a proteolytic enzyme that is a typical bioactive molecule, on fine particles of a $\mathrm{Fe}_{3} \mathrm{O}_{4}-\gamma \mathrm{Fe}_{2} \mathrm{O}_{3}$ mixed solution

\footnotetext{
${ }^{*}$ Corresponding author e-mail: nguyentienthangitb@yahoo.com
} 
while they are synthesized. The synthesis was performed in the open air at temperature as low as $4^{\circ} \mathrm{C}$ and on nearneutral conditions of $\mathrm{pH}=7$ - 9; most bioactive molecules as well as trypsin can exist stable during the synthesis process.

\section{EXPERIMENT}

A reaction solution $(\mathrm{pH}=2.0,50 \mu \mathrm{l})$ of $\mathrm{FeCl}_{2}(2.5 \mu \mathrm{mol})+\mathrm{FeCl}_{3}(2.5 \mu \mathrm{mol})$ and a $\mathrm{pH}$ adjusting solution $(50 \mathrm{ml})$ of $\mathrm{NH}_{4} \mathrm{OH}$ are simultaneously dropped to an aqueous solution $(100 \mathrm{ml})$ which contains $0-1 \mathrm{mg}$ of trypsin in a microtube (1.5 ml in volume) in the open air (Fig. 1). The mixed aqueous solution was kept at $\sim 4^{\circ} \mathrm{C}$ by ice. Introducing air bubbles using a pipette into the mixed solution, part of the $\mathrm{Fe}^{2+}$ ions are oxidized to $\mathrm{Fe}^{3+}$, which resulted in the synthesis of $\mathrm{Fe}_{3} \mathrm{O}_{4}$ particles. Since trypsin, and most biomaterials as well, are stable only on near-neutral condition of $\sim 7 \leq \mathrm{pH} \leq \sim 9$, we so adjusted the amount of the added $\mathrm{NH}_{4} \mathrm{OH}$ solution that the $\mathrm{pH}$ value of the trypsin aqueous solution became $\sim 9$ after adding the reaction and $\mathrm{pH}$ adjusting solutions. We separated the synthesized magnetite fine particles from the aqueous solution using a magnet ( 600 Oe in magnetic field strength on the surface).

We estimated the amount of the immobilized trypsin by an amino acid analysis method [2] and an enzymatic activity analysis method [3].

The samples were subjected to $\mathrm{x}$-ray diffraction (XRD) analyses using $\mathrm{Cu} K \mathrm{a}$ radiation and to transmission electron microscope (TEM) observations.

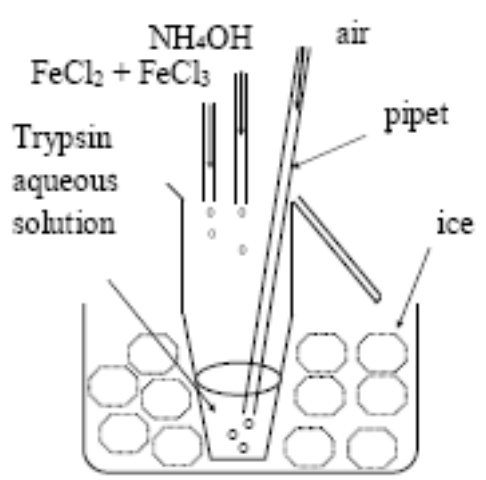

Fig. 1: Direct immobilization of trypsin onto ferrite fine particles while they are synthesized utilizing air oxidation of $\mathrm{Fe}^{2+} ! \mathrm{Fe}^{3+}$.

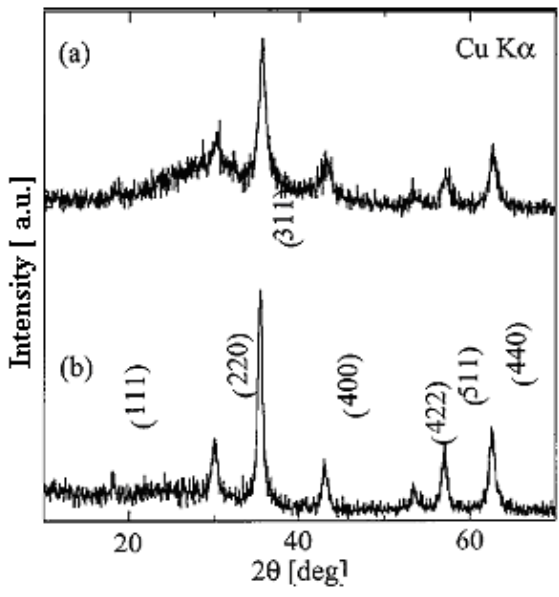

Fig. 2: Typical XRD diagrams for ferrite fine particles synthesized $(a)$ with and $(b)$ without trypsin added into the aqueous solution.

\section{RESULTS AND DISCUSSION}

The XRD measurements (Fig. 2) revealed that particles synthesized from trypsin containing aqueous solution, as well as those synthesized without trypsin, are of single phase with a spinel structure of a mixed solution between $\mathrm{Fe}_{3} \mathrm{O}_{4}$ and $\gamma \mathrm{Fe}_{2} \mathrm{O}_{3}$. When synthesized with trypsin the XRD lines are larger in width and weaker in strength than when synthesized without trypsin. This suggests that the particles synthesized with trypsin are smaller (than those synthesized without trypsin) and are combined with trypsin that absorbs the x-ray beams. The TEM observation (Fig. 3) supported this. When synthesized under the presence of trypsin we obtained 
images of particles, about $8 \mathrm{~nm}$ in average size, surrounded by clouds (which may be trypsin), while when synthesized without trypsin we obtained images of the particles of about $10 \mathrm{~nm}$ in average size.

Figure 4 shows the amount of trypsin immobilized on the magnetite particles plotted as a function of the amount of trypsin contained in the aqueous solution. The data are reliable since the measured values by two different methods almost agree. The amount of immobilized trypsin increases with the amount in the aqueous solution, and the rate of increase becomes low as the amount in the aqueous solution increases. When $0.4 \mathrm{mg}$ of trypsin is contained in the aqueous solution, about $40 \%$ of trypsin in the solution is immobilized, which means that seven trypsin molecules are bound on the average per ferrite particle.
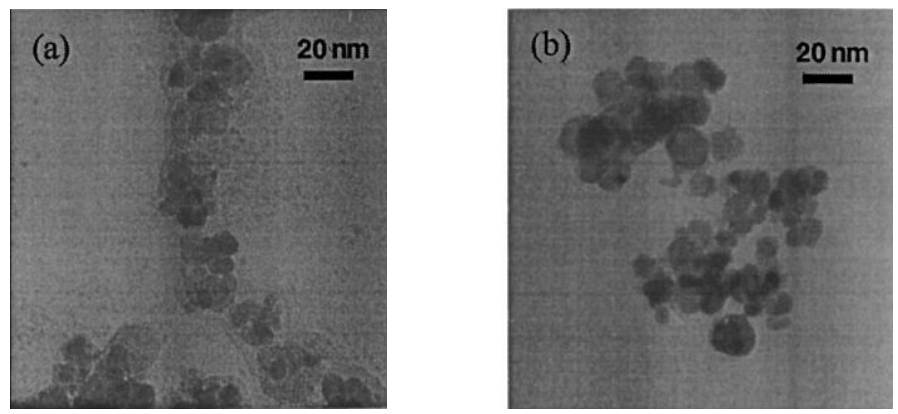

Fig. 3: Typical TEM images for ferrite fine particles synthesized (a) with and (b) without trypsin added into the aqueous solution.

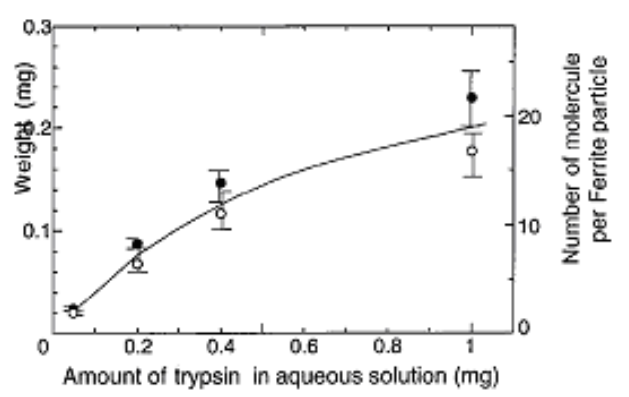

Fig. 4: Amount of trypsin immobilized on $\mathrm{Fe}_{3} \mathrm{O}_{4}$ particles, in weight or in number of molecule per a particle, which is plotted vs amount of trypsin in aqueous solution. Closed and open circles show the date obtained by amino acid analysis and enzymatic activity analysis methods, respectively.

\section{CONCLUSION}

Trypsin was successfully immobilized onto the surfaces of the $\mathrm{Fe}_{3} \mathrm{O}_{4}-\gamma \mathrm{Fe}_{2} \mathrm{O}_{3}$ fine particles, $\sim 8$ $\mathrm{nm}$ in size, during the synthesis of the particles at about $4{ }^{\circ} \mathrm{C}$ and $\mathrm{pH} \sim 9$ in the open air. The low temperature, near-neutral condition is compatible with most bioactive molecules (e.g., DNA, antibodies, drugs, etc.) as well as enzymes including trypsin used in this study. Therefore, our technique will be useful to directly bind a variety of bioactive molecules onto $\mathrm{Fe}_{3} \mathrm{O}_{4}-\gamma \mathrm{Fe}_{2} \mathrm{O}_{3}$ particles for biomedical applications utilizing magnetic separation technique. 


\section{ACKNOWLEDGEMENT}

The present study has been financially supported by the basic research program from the Ministry of Science and Technology of Vietnam

\section{REFERENCES}

1. Tran Hoang Hai (2005), Magnetic nanoparticles and their applications in biomedicine, The second German-Vietnam Summer Schoole on Modern Optics and New Materials, Ho Chi Minh City, 151.

2. Cohen, S.A. and Strydom, D.J. (1988), Anal. Biochem. 174, 1.

3. Lottenberg, R., Christensen, U., Jackson, C.M., and Coleman, P.L. (1981), Methods Enzymol. 80, 341. 